\title{
Bacteriological Profile of Blood Culture Positive Sepsis in Newborn at BPKIHS, Dharan Nepal
}

\author{
Piush Kanodia, Sunil Kumar Yadav, Rupa Rajbhandari Singh, Nisha K Bhatta \\ Department of Pediatrics and Adolescent Medicine, B.P. Koirala Institute of Health Sciences (BPKIHS), \\ Dharan, Nepal
}

\begin{abstract}
Correspondence
Dr. Piush Kanodia,

Department of Pediatrics and

Adolescent Medicine,

BP Koirala Institute of Health

Sciences, Dharan, Nepal

Email:

piushkanodia@yahoo.com

DOI: http://dx.doi.org/10.3126/ jcmsn.v13i1.16663

Article received: Sept $25^{\text {th }} 2016$ Article accepted: J an $20^{\text {th }} 2017$

ABSTRACT

Background \& Objectives: Neonatal infections currently cause about 1.6 million deaths annually in developing countries. Sepsis and meningitis is responsible for most of these deaths. This study was undertaken to determine the bacteriological profiles and antibiotic sensitivity patterns of isolates from blood cultures of neonates admitted in a tertiary care hospital in Eastern Nepal. Materials \& Methods: A retrospective study was conducted at pediatric department from January, 2014 to December 2014. Total 1009 newborns blood sample with suspected and clinical sepsis were cultured by using standard microbiological technique and antibiotic sensitivity patterns were studied. Results: The positive blood culture was 32.4\% (327/1009). Gram positive bacteria were more common $231(71 \%)$ than gram negative bacteria 96(29\%). Staphylococcus aureus 174 (53.2\%) and acinetobacter $46(14.1 \%)$ were the commonest isolates in blood culture. Most of the organisms showed sensitivity with aminoglycosides (gentamicin and amikacin) and third generation cephalosporins. Conclusion: Staphylococcus aureus, Acinetobacter and Klebsiella species remain the principal organisms causing neonatal sepsis and antibiotics like amino glycosides should be first choice of drugs.
\end{abstract}

Key words: Blood culture; Neonatal sepsis; organism

Citation: Kanodia P, Yadav SK, Singh RR, Bhatta NK. Bacteriological Profile of Blood Culture Positive Sepsis in Newborn at BPKIHS, Dharan Nepal. JCMS Nepal. 2017;13(1):193-6.

\section{INTRODUCTION}

Neonatal sepsis is a significant cause of neonatal morbidity and mortality in the newborn, particularly in preterm, low birth weight infants. ${ }^{1,2}$ According to World Health Organization (WHO) estimates; neonatal sepsis remains the major cause out of five million neonatal deaths per year. ${ }^{3}$ The spectrum of organisms that causes neonatal sepsis changes over times and varies from region to region. This is due to the changing pattern of antibiotic use and changes in life style. Neonatal sepsis caused by Gram-negative organisms has been reported in recent years from $\mathrm{Nepal}^{4-6}$ and responsible for Neonatal sepsis caused by responsible for 18 to $78 \%$ of all neonatal sepsis. ${ }^{711}$ In the developing world, Escherichia coli (E. coli), Klebsiella species, and Staphylococcus aureus (S. aureus) are the most common pathogens of EOS, whereas $S$. aureus, Streptococcus pneumoniae, and Streptococcus pyogenes are the most commonly reported organisms in LOS. ${ }^{12,13}$ But Group B streptococcal disease is the most important cause of neonatal sepsis in Europe and North America. ${ }^{6}$ Thus, the knowledge of both the common pathogens causing septicemia in neonates and their antimicrobial susceptibility is essential in order to select appropriate antimicrobial treatment. Hence, the present study was conducted to document the bacteriological profile of neonatal septicemia and their antibiotic susceptibility profile for planning strategy for the management of neonatal septicemia of neonates admitted in a tertiary care hospital in eastern region of Nepal.

\section{MATERIALS AND METHODS}

This A retrospective study was conducted at neonatology division of BPKIHS from January, 2014 to December 2014. Total 1009 newborns blood sample with suspected and clinical sepsis were cultured by using standard microbiological 
technique and antibiotic sensitivity patterns were studied. One $\mathrm{ml}$ of blood collected under aseptic conditions was inoculated in blood culture bottle containing $9 \mathrm{ml}$ of Brain Heart Infusion broth and incubated at $37^{\circ} \mathrm{C}$. Total 1009 newborns blood samples were deposited in microbiology lab to know causative organism and antibiotic sensitivity pattern by using standard microbiology technique. Subcultures were made into sheep blood agar, chocolate agar, and MacConkey agar after overnight of aerobic incubation. Blood agar and MacConkey agar plates were incubated overnight at $37^{\circ} \mathrm{C}$ in aerobic atmosphere while chocolate agar plates were incubated overnight at $37^{\circ} \mathrm{C}$ in $5 \%$ $\mathrm{CO} 2$ atmosphere. Thereafter, culture bottles were observed for turbidity for up to 10 days. Final blind subcultures were done before reporting the sample negative. ${ }^{14}$ Antimicrobial susceptibility of the bacterial isolates to antibiotics namely amikacin, ampicillin, cefotaxime, ciprofloxacin, methicillin and gentamicin was determined by Kirby Bauer's disc diffusion method.

\section{RESULTS}

PATIENTS: Out of 1009 newborns blood cultures, $327(32.4 \%)$ were positive for bacterial pathogens.

ORGANISMS: Gram-positive organism were isolated in $231(71 \%)$ and gram-negative organism in $96(29.0 \%)$. Staphylococcus aureus in 174 $(53.2 \%)$, Enterococcus in $12(3.6 \%)$, coagulase negative Staphylococcus in $8(2.4 \%)$, Streptococcus $11(3.4 \%)$ and MRSA $26(7.9 \%)$ were the grampositive organisms isolated. Among the Gramnegative organisms Klebsiella pneumoniae in 8 $(2.4 \%)$, Enterobacter $\mathrm{Sp}$ in $10 \quad(3.1 \%)$ and Acinetobacter in $46(14.1 \%)$ were the most common. Citrobacter $(0.91 \%)$, Pseudomonas $(5.5 \%)$ and E.coli $(3.4 \%)$ were the other isolates. (TABLE 1).

ANTIBIOTIC RESISTANCE: Resistance to ampicillin $(>50 \%)$ was observed in both gram positive and negative bacteria. Methicillin resistance was seen in $16 \%$ of Staph aureus isolates. Resistance to aminoglycosides, gentamicin (20t o $40 \%$ ) and amikacin (0 to $12 \%$ ) was low. Resistance to $3^{\text {rd }}$ generation cephalosporins and ciprofloxacin ranged from $0-30 \%$ (Table 2 ).

\section{DISCUSSION}

In this study, blood culture positivity rate is $32.4 \%$ and in $67.6 \%$ cases there was no growth. This finding is comparable with other reports. ${ }^{15,16} \mathrm{~A}$ negative blood culture does not exclude sepsis and could be due to anaerobes. ${ }^{17}$ In this study the predominant isolates was $\mathrm{S}$. aureus which is in agreement with other reports. ${ }^{17,18}$ In this study, Klebsiella species $(2.4 \%)$, Enterobacter species (3.1\%) and Acinetobacter (14.1\%) are the leading cause of neonatal sepsis among gram negative organisms. The report of the National Neonatal Perinatal database showed Klebsiella as the predominant $(29 \%)$ pathogen. ${ }^{19,20}$ The clinical significance of relatively low virulence isolates, such as CONS and Enterococcus is difficult to ascertain. These organisms can cause true bacteremia or their isolation may represent simple contamination. It would be unfair to ignore such isolates as contaminants.

In contrast to many other studies that reported Klebsiella and other gram-negative organism and Staph. aureus as the common isolates. ${ }^{15,21,22}$ In the present study, majority of patients showing predominantly Staph aureus. Being a tertiary care hospital, complicated pregnancies in labour are referred to BPKIHS. Premature rupture of membrane and repeated vaginal examinations by the midwives were the common factors observed on admissions. Staph aureus is not a common organism in the genital tract. Hence it was presumed that possibly due to poor knowledge of

\begin{tabular}{|c|c|c|}
\hline $\begin{array}{l}\text { TOTAL NUMBER OF } \\
\text { ORGANISM ISOLATED }\end{array}$ & \multicolumn{2}{|c|}{ 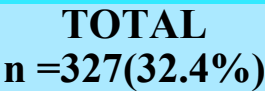 } \\
\hline $\begin{array}{l}\text { GRAM POSITIVE } \\
\text { BACTERIA }\end{array}$ & 231 & $71 \%$ \\
\hline Staphylococcus aureus & 174 & $53.2 \%$ \\
\hline Enterococcus Fecalis & 12 & $3.6 \%$ \\
\hline $\begin{array}{l}\text { Coagulase negative } \\
\text { Staphylococcus }\end{array}$ & 8 & $2.4 \%$ \\
\hline Streptococcus & 11 & $3.4 \%$ \\
\hline$M R S A$ & 26 & $7.9 \%$ \\
\hline $\begin{array}{l}\text { GRAM NEGATIVE } \\
\text { BACTERIA }\end{array}$ & 96 & $29 \%$ \\
\hline Klebsiella pneumoniae & 8 & $2.4 \%$ \\
\hline Enterobacter & 10 & $3.1 \%$ \\
\hline Acinetobacter & 46 & $14.1 \%$ \\
\hline E.Coli & 11 & $3.4 \%$ \\
\hline Pseudomonas & 18 & $5.5 \%$ \\
\hline Citrobacter & 3 & $0.91 \%$ \\
\hline
\end{tabular}




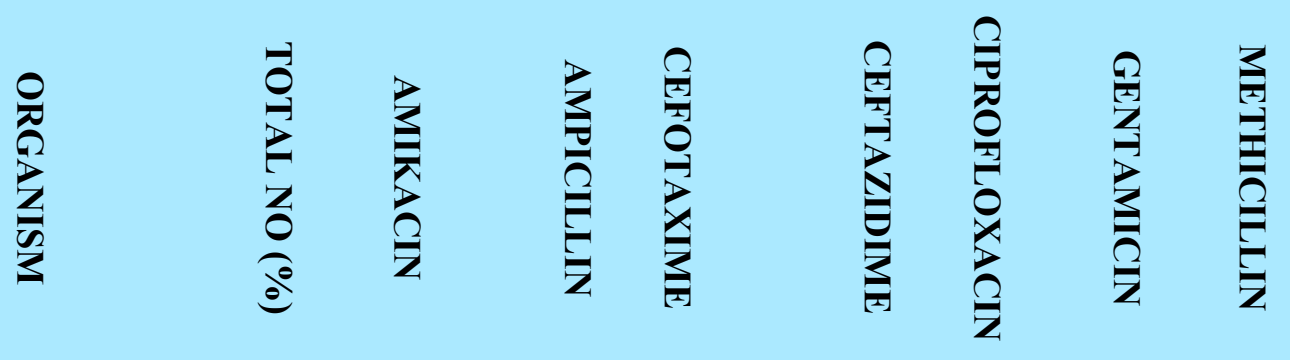

GRAM POSITIVE BACTERIA

\begin{tabular}{|ccccccccc|}
\hline Staphylococcus aureus & $174(53.2 \%)$ & 3 & 59 & 8 & 3 & 28 & 19 & 16 \\
\hline Enterococcus Fecalis & $12(3.6 \%)$ & 13 & 12 & 17 & 3 & 17 & 20 & - \\
\hline $\begin{array}{c}\text { Coagulase negative } \\
\text { Staphylococcus }\end{array}$ & $8(2.4 \%)$ & 8 & 33 & 8 & 0 & 17 & 25 & - \\
\hline Streptococcus & $11(3.4 \%)$ & 0 & 25 & 50 & 0 & 0 & 0 & - \\
MRSA & $26(7.9 \%)$ & 7 & 20 & 15 & 3 & 2 & 18 & 3 \\
\hline $\begin{array}{c}\text { GRAM POSITIVE } \\
\text { BACTERIA }\end{array}$ & $\mathbf{9 6 ( 2 9 \% )}$ & & & & & & &
\end{tabular}

\begin{tabular}{|ccccccccc|}
\hline Klebsiella pneumoniae & $8(2.4 \%)$ & 11 & 58 & 14 & 6 & 14 & 42 & - \\
\hline Enterobacter & $10(3.1 \%)$ & 3 & 63 & 13 & 13 & 14 & 42 & - \\
Acinetobacter & $46(14.1 \%)$ & 12 & 68 & 28 & 12 & 24 & 40 & - \\
\hline E.Coli & $11(3.4 \%)$ & 5 & 58 & 11 & 16 & 11 & 42 & - \\
\hline Pseudomonas & $18(5.5 \%)$ & 5 & - & 16 & 16 & 26 & 21 & - \\
\hline Citrobacter & $3(0.91 \%)$ & 0 & 58 & 0 & 0 & 17 & 25 & -
\end{tabular}

disinfection and sterilization in domiciliary practice, or a higher rate of survival of highly susceptible low-birth weight infants, admitted to neonatal intensive care units, acquire this infection from several sources.

Resistance to ampicillin was seen to the tune of $59 \%$ in GPC and $68 \%$ in GNB, which is in agreement with many other studies. Staph aureus showed resistance $(16 \%)$ to methicillin an observation also made in other studies. ${ }^{18,23,24}$ Most of the organisms are sensitive to aminoglycosides (Amikacin and gentamicin) and third generation cephalosporins. A combination of ampicillin and amikacin is the treatment of choice for Neonatal sepsis at BPKIHS. In general, the sensitivity of the gram negative isolates to amikacin supports continued use of this agent in the initial, empiric treatment of neonatal sepsis in our hospital.

\section{CONCLUSION}

Thus, it is concluded that $\mathrm{S}$ aureus, CONS, and gram negative organisms (Klebsiella, Enterobacter and E. coli) are the leading cause of neonatal sepsis in Nepal and most of them are sensitive to aminoglycosides and third generation cephalosporins. Continuous surveillance is needed to understand changing bacterial ecology and the resistance pattern of the antimicrobial agents in a neonatal unit so that an empirical treatment of critically ill or very low birth weight infants could be initiated pending a report of blood culture and sensitivity. Moreover, a decline in infection rate is a great motivation for health care workers for following the infection control practices in the neonatal units.

\section{REFERENCES}

1. Stoll BJ, Hansen N. Infections in VLBW infants: studies from the NICHD Neonatal Research Network. Semin Perinatol. 2003 Aug;27 (4): 293-301. DOI: 10.1016/S01460005(03)00046-6.

2. Stoll BJ, Hansen NI, Adams-Chapman I, Fanaroff AA, Hintz SR, Vohr B, et al. Neurodevelopmental and growth impairment among extremely low-birth-weight infants with neonatal infection. JAMA. 2004 Nov 17;292 (19): 2357-65. DOI: 10.1001/jama.292.19.2357. PMID: 15547163.

3. WHO. Perinatal Mortality. Geneva: WHO/FRH/ MSM, 
1996.

4. Khanal B. Neonatal septicaemia: a hospital based study in Eastern Nepal. JNM A. 2004;43 (155): 231-4.

5. Jain NK, Jain VM, Maheshwari S. Clinical profile of neonatal sepsis. Kathmandu Univ Med J (KUMJ). 2003 Apr-Jun;1 (2): 117-20.

6. Fischer G, Horton RE, Edelman R. From the National Institute of Allergy and Infectious Diseases. Summary of the National Institutes of Health workshop on group B streptococcal infection. J Infect Dis. 1983 Jul;148 (1): 1636. DOI: 10.1093/infdis/148.1.163. PMIDd: 6350487.

7. Couto RC, Carvalho EA, Pedrosa TM, Pedroso ER, Neto MC, Biscione FM. A 10-year prospective surveillance of nosocomial infections in neonatal intensive care units. Am J Infect Control. 2007 Apr;35 (3): 183-9. DOI: 10.1016/ j.ajic.2006.06.013. PMID: 17433942.

8. Stoll BJ, Hansen N, Fanaroff AA, Wright LL, Carlo WA, Ehrenkranz RA, et al. Late-onset sepsis in very low birth weight neonates: the experience of the NICHD Neonatal Research Network. Pediatrics. 2002 Aug;110 (2 Pt 1): 28591. DOI: 10.1542/peds.110.2.285. PMID: 12165580.

9. Kamath S, Mallaya S, Shenoy S. Nosocomial infections in neonatal intensive care units: profile, risk factor assessment and antibiogram. Indian J Pediatr. 2010 Jan;77 (1): 37-9. DOI: 10.1007/s12098-010-0005-5. PMID: 20135266.

10. Tseng YC, Chiu YC, Wang JH, Lin HC, Lin HC, Su BH, et al. Nosocomial bloodstream infection in a neonatal intensive care unit of a medical center: a three-year review. J Microbiol Immunol Infect. 2002 Sep;35 (3): 168-72. PMID: 12380789.

11. Macharashvili N, Kourbatova E, Butsashvili M, Tsertsvadze T, McNutt LA, Leonard MK. Etiology of neonatal blood stream infections in Tbilisi, Republic of Georgia. Int J Infect Dis. 2009 Jul;13 (4): 499-505. DOI: 10.1016/j.ijid.2008.08.020. PMID: 19058989.

12. Zaidi AK, Thaver D, Ali SA, Khan TA. Pathogens associated with sepsis in newborns and young infants in developing countries. Pediatr Infect Dis J. 2009 Jan;28 (1 Suppl): S10-8. DOI: 10.1097/INF.0b013e3181958769. PMID: 19106757.

13. K. Mulholland PM, K. Mason et al. Bacterial etiology of serious infections in young infants in developing countries: results of a multicenter study. The WHO Young Infants Study Group. Pediatr Infect Dis J. 1999 Oct;18 (10 Suppl): S17-22.

14. Isenbergh HD. Clinical Microbiology Procedures Handbook. 2nd edition. Washington, DC, USA: ASM Press; 2004.

15. Mathur M, Shah H, Dixit K, Khambadkone S, Chakrapani A, Irani S. Bacteriological profile of neonatal septicemia cases (for the year 1990-91). J Postgrad Med. 1994 JanMar;40 (1): 18-20. PMID: 8568708.

16. Mondal GP, Raghavan M, Bhat BV, Srinivasan S. Neonatal septicaemia among inborn and outborn babies in a referral hospital. Indian J Pediatr. 1991 Jul-Aug;58 (4): 529 -33. DOI: 10.1007/BF02750936. PMID: 1800336.

17. Chow AW, Leake RD, Yamauchi T, Anthony BF, Guze LB. The significance of anaerobes in neonatal bacteremia: analysis of 23 cases and review of the literature. Pediatrics. 1974 Dec;54 (6): 736-45. PMID: 4431671.

18. Karthikeyan G, Premkumar K. Neonatal sepsis: Staphylococcus aureus as the predominant pathogen. Indian J Pediatr. 2001 Aug;68 (8): 715-7. DOI: 10.1007/ BF02752407. PMID: 11563247.

19. Thomas M, Padmini B, Srimathi G, Sundararajan V, Raju BA. Microbial profile of neonatal infection in Coimbatore. Indian J Pediatr. 1999 Jan-Feb;66 (1): 11-4. DOI: 10.1007/ BF02752342. PMID: 10798030.

20. Neonatal morbidity and mortality: report of the National Neonatal-Perinatal Database. Indian Pediatr. 1997 Nov;34 (11): 1039-42. PMID: 9567538.

21. Grauel EL, Halle E, Bollmann R, Buchholz P, Buttenberg $\mathrm{S}$. Neonatal septicaemia--incidence, etiology and outcome.
A 6-year analysis. Acta Paediatr Scand Suppl. 1989;360: 113-9. DOI: 10.1111/j.1651-2227.1989.tb11291.x. PMID: 2642246.

22. Kuruvilla KA, Pillai S, Jesudason M, Jana AK. Bacterial profile of sepsis in a neonatal unit in south India. Indian Pediatr. 1998 Sep;35 (9): 851-8. PMID: 10216593.

23. Jesudason MV, Anandaraj WS, Jegadeesan P. Incidence of methicillin resistant coagulase positive \& coagulase negative staphylococci in blood cultures. Indian J Med Res. 1997 Apr;105: 155-7. PMID: 9145596.

24. Vidhani S, Mehndiratta PL, Mathur MD. Study of methicillin resistant S. aureus (MRSA) isolates from high risk patients. Indian J Med Microbiol. 2001 Apr-Jun;19 (2): 13-6. PMID: 17664799. 